Case Report

\title{
CONGENITAL TUBERCULOSIS IN AN INFANT - EPIDEMIOLOGICAL INVESTIGATION
}

\author{
Kharate $\mathrm{A}^{1}$, Khurana $\mathrm{J}^{2}$, Patidar $\mathrm{M}^{3}$, Doshi $\mathrm{N}^{3}$ \\ ${ }^{1}$ State TB Officer, M. P., India \\ ${ }^{2}$ Intermediate Reference Laboratory, MRTB Hospital and Chest Centre, Indore, M. P. India \\ ${ }^{3}$ MRTB Hospital and Chest Centre, Indore, M. P. India
}

\begin{abstract}
Congenital Tuberculosis was diagnosed in a 40-days-old premature infant. The infant had fever. A chest radiograph showed infiltrates which was thought to be bacterial infection. Gastric aspirate revealed acidfast bacilli by Ziehl-Neelsen staining and fluorescent microscopy later confirmed to be Mycobacterium tuberculosis by Gene Xpert MTB/RIF test. Her 22 years old mother was later diagnosed as a case of tuberculosis with symptoms, signs and radiologic manifestation of mild pleural effusion with infiltration. Infant was treated with isoniazid, syrup rifampicin, pyrazinamide and pyridoxine and mother with RNTCP Cat I regimen.
\end{abstract}

Key-words: Gastric Aspirate; Tuberculosis; Ziehl-Neelsen; Congenital; Gene Xpert MTB/RIF Test

\section{INTRODUCTION}

Tuberculosis (TB) is a global public health problem, India and China together account for almost 40 percent of the world's TB. ${ }^{1}$ Congenital tuberculosis (TB) is a rare entity with 300 cases reported so far $^{2}$ and only 11 cases from India. ${ }^{3}$ Approximately 30 cases of congenital TB have been reported since the review in 1980 by Hageman, et al. ${ }^{4}$ The transmission of tubercular bacilli to the foetus occurs by haematogenous spread through placenta, in-uterus aspiration and ingestion of infected amniotic fluid or secretions during delivery. In addition, post natal infection may occur from contact with a contagious mother or ingestion of infected breast milk from a mother with tuberculosis breast abscess. $^{5}$

\section{CASE REPORT}

A 40 day old female infant, weighing $3000 \mathrm{gm}$, presented to us with a history of fever for 20 days,

\author{
Correspondence: \\ Dr. Jyoti Khurana \\ Microbiologist \\ MRTB Hospital/Chest Centre, Indore, \\ Madhya Pradesh, India \\ E-mail: dr.jyotikhurana@yahoo.com
}

fast breathing for 2 days and refusal to feed for one day. The baby was delivered as full term by spontaneous vaginal delivery with birth weight of $2750 \mathrm{gm}$. Physical examination revealed a febrile $\left(102^{\circ} \mathrm{F}\right)$. Investigations revealed: Haemoglobin: $9.4 \mathrm{gm} / \mathrm{dl}$, Platelet 86,000 with total WBC 850/ CU mm, 60\% Neutrophils, 32\% Lymphocytes, 4\% Monocytes and 4\% Eosinofils. Erythrocyte sedimentation rate was $6 \mathrm{~mm}$ after the $1^{\text {st }}$ hour. Cerebrospinal fluid examination was normal. Serum electrolytes, creatinine, urea and blood sugar were normal. Ultrasound Sonography Test was showing liver normal in size and shape Parenchymal echotexture was homogenous. Spleen was enlarged $(5.6 \mathrm{~cm})$, multiple small hypoxic well defined round to oval lesions were seen throughout splenic parenchyma (granuloma). Splenomegaly with splenic microabcess and lymphoma of spleen was seen. The chest radiograph showed parenchymal infiltration in both lung fields (figure-1).

Gastric aspirate showed Mycobacterium tuberculosis by Gene Xpert MTB/RIF test. Acid Fast Bacilli were seen by florescent microscopy and Zeihl-Nelson staining. The infant's family was screened for tuberculosis. Only her mother was found to be the source of infection. Her chest radiograph showed evidence of pleural effusion, 
which was confirmed by a diagnostic pleural fluid. The pleural fluid was pale yellow with a cobweb coagulum formation. The pleural fluid Adenosin deaminase was $38 \mathrm{IU} / \mathrm{l}$. The cytochemical examination of pleural fluid showed total leukocyte count of 1500 cells/cu mm, 10\% Polymorphs and 90\% Lymphocytes, protein : $3.4 \mathrm{~g} / \mathrm{dl}$ and sugar : $50.4 \mathrm{mg} / \mathrm{dl}$. Left mild pleural effusion with basal lung vasodilatation was also seen. (figure 2)

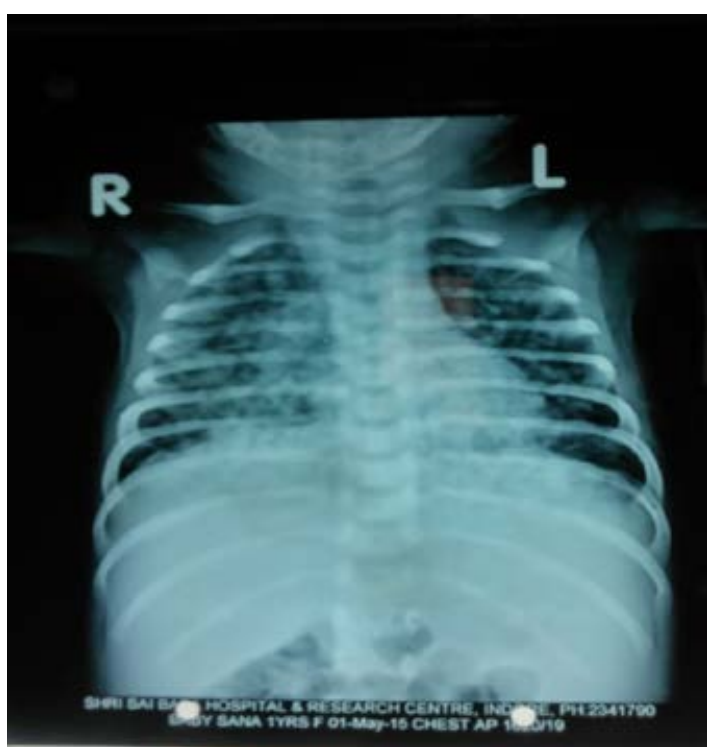

Figure 1. Chest X-Ray of infant showing parenchymal infiltration in both lung fields.

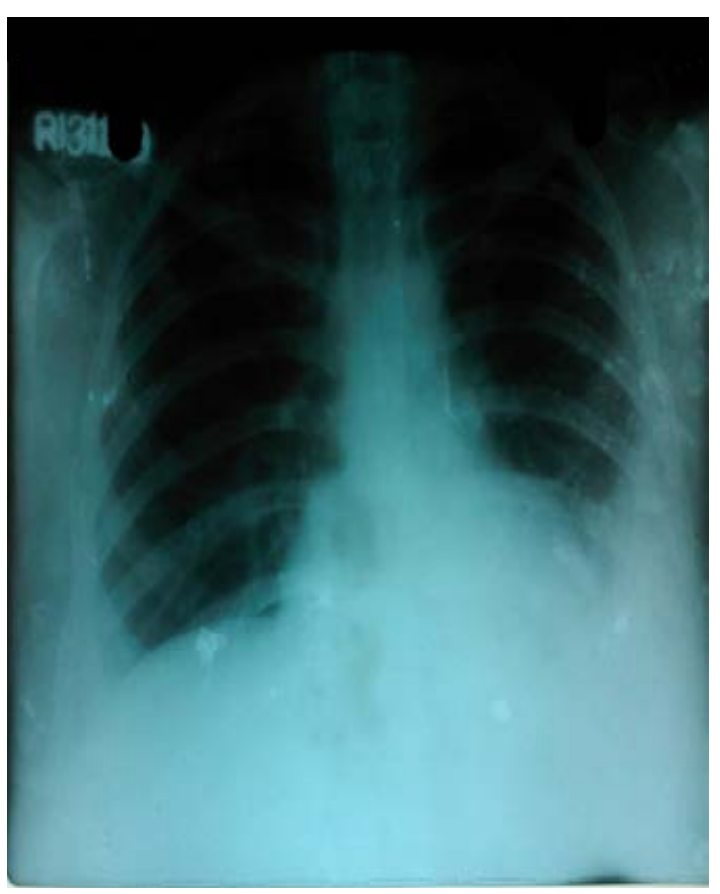

Figure 2. Chest X-Ray of her mother showing pleural effusion in lung fields

\section{DISCUSSION}

The diagnosis of congenital TB is often difficult. The clinical features of congenital TB have been described by Hudson (1956). ${ }^{6}$ Cantwell et al ${ }^{7}$ have proposed revised diagnostic criteria for the diagnosis of congenital TB. The infant must have proved tuberculous lesions and at least one of the following: (i) Lesions in the first week of life; (ii) A primary hepatic complex or caseating hepatic granulomas (iii) Tuberculous infection of the placenta or the maternal genital tract or (iv) Exclusion of the possibility of postnatal transmission by a thorough investigation of contacts, including the infant's hospital attendants and by adherence to existing recommendations for treating infants exposed to tuberculosis. ${ }^{7}$ In our case only her mother was diagnosed with pulmonary tuberculosis after screening. Spleen of infant was with multiple hypoxic lesions throughout splenic parenchyma.

Although gastric aspirate cultures are said to be a poor diagnostic tool. ${ }^{8}$ It has been associated with a high yield of positive cultures for Mycobacterium tuberculosis in most of the reported cases of congenital tuberculosis. In our patient, Gene Xpert MTB/RIF test of her gastric aspirate showed the presence of Mycobacterium tuberculosis and Rifampicin sensitive. Our patient has respiratory distress and hepatosplenomegaly. The milliary pattern in her chest radiograph was the clue that prompted us to get a chest radiograph of the mother. This led to further investigations that conclusively documented tuberculosis in order to start anti-tuberculosis therapy.

In infants who are suffering from pneumonia, it is advisable to send their gastric aspirate/lavage for Gene Xpert MTB/RIF test so that diagnosis of tuberculosis becomes as early as possible.

\section{REFERENCES}

1. Global tuberculosis Report 2012. (WHO/HTM/ TB/2012) Geneva: World Health Organization.

2. Cantwell M, Snider DE Jr, Cauthen G, et al. Epidemiology of tuberculosis in the United States, 1985 through 1992. JAMA 1994; 272:535-539

3. Kumar R, Gupta N, Sabharwal A, S. Congenital tuberculosis. Indian J Pediatr 2005;72:631-633. 
4. Hageman J, Shulman S, Schreiber M, Luck S, Yogev R. Congenital tuberculosis: critical reappraisal of clinical findings and diagnostic procedures. Pediatrics 1980; 66:980-984.

5. Pablo JS, Amina A.Tuberculosis in Taeusch HW, Ballard RA, and Gleason CA: Avery's Diseases of the Newborn.8th ed. Philadelphia: W.B. Saunders 2005:542-547.
6. Hudson FP. Clinical aspects of congenital tuberculosis. Arch Dis Child 1956;31:136-139.

7. Cantwell MF, Shehab ZM, Costello AM, et al. Brief report: congenital tuberculosis. N Engl J Med 1994;330:1051-1054.

8. Kendig EL Jr: Prognosis of infants born of tuberculous mothers. Pediatrics 1960;26:97. 